\title{
Prevalence of depression and anxiety and their association with body mass index among high school students in Qazvin, Iran, 2013-2014
}

\author{
Maryam Javadi ${ }^{1,2}$, Zinat Jourabchi ${ }^{3}$, Ali Akbar Shafikhani ${ }^{4}$, Esra Tajik ${ }^{5,6}$
}

\author{
${ }^{1}$ Ph.D. of Nutrition, Associate Professor, Department of Nutrition, School of Health, Qazvin University of Medical \\ Sciences, Qazvin, Iran \\ ${ }^{2}$ Children Growth Research Center, Qazvin University of Medical Sciences, Qazvin, Iran \\ ${ }^{3}$ Ph.D. of Community Health, Assistant Professor, Department of Midwifery, Faculty of Nursing and Midwifery, \\ Qazvin University of Medical and Health Sciences, Qazvin, Iran \\ ${ }^{4}$ M.Sc. of Occupational Health Engineering, Children Growth Research Center, Qazvin University of Medical \\ Sciences, Qazvin, Iran \\ ${ }^{5}$ Ph.D. of Community Nutrition, Department of Nutrition and Dietetics, Faculty of medicine and Health Sciences, \\ Universiti Putra Malaysia, Serdang, Malaysia \\ ${ }^{6}$ Ph.D. of Community Nutrition, Postdoctoral Researcher, Faculty of Nutrition Sciences and Food Technology \\ Shahid Beheshti University of Medical Sciences, Tehran, Iran
}

\section{Type of article: Original}

\begin{abstract}
Background: Evidence shows that mental disorders among adolescents are associated with suicide, drug abuse, acute infectious diseases and low educational performances.

Objective: To determine the prevalence of depression and anxiety and their associations with body mass index (BMI) among high school students in Qazvin, Iran in 2013-2014.

Methods: A descriptive and analytical cross-sectional study using cluster-sampling method recruited 1,040 students among high schools in Qazvin, Iran from March 2013 to April 2014. Data were collected using questionnaires including demographic, Beck depression inventory and Beck anxiety inventory, and were analyzed with SPSS-19 by descriptive analyses, t-test, Chi-square and Pearson correlation.

Results: The prevalence of depression and anxiety was $31.8 \%$ and $14.9 \%$, respectively and these amounts were significantly higher in girls than in boys $(\mathrm{p}<0.05)$. Respondents showed $23.75 \%$ and $11.07 \%$ mild to moderate symptoms of depression and anxiety, respectively as well as 8.08 and $3.75 \%$ severe symptoms of depression and anxiety, respectively. There was a positive and significant association between depression and anxiety $(\mathrm{r}=0.256$, $\mathrm{p}<0.001)$ and between depression and body mass index $(\mathrm{BMI})(\mathrm{r}=0.333, \mathrm{p}<0.001)$, however there was an inverse association between anxiety and BMI $(\mathrm{r}=0.086, \mathrm{p}<0.006)$.

Conclusion: The current study made a significant step forward in assessment of mental disorders and BMI to show the significance of depression and anxiety among adolescents in Qazvin. Therefore, effective interventions are necessary to improve this situation as well as the evaluation of the effectiveness of the interventions.

Keywords: Mental disorders; Anxiety; Depression; Adolescent, Body mass index
\end{abstract}

\section{Introduction}

Adolescence is one of the important and crucial life stages and usually, this period comes with mental and spiritual changes (1). The social issues to cope with sex roles are thoughts which dramatically increase simultaneously with advancing toward maturity $(1,2)$. This restriction can reduce opportunities and choices among adolescents,

\section{Corresponding author:}

Dr. Esra Tajik, Department of Nutrition and Dietetics, Faculty of medicine and Health Sciences, Universiti Putra Malaysia, 43400 Serdang, Selangor, Malaysia; and Faculty of Nutrition Sciences and Food Technology Shahid Beheshti University of Medical Sciences, Tehran, Iran.

Tel: +98.9102244700, Fax: +98.2122671935, Email: a_tjk@yahoo.com

Received: December 05, 2016, Accepted: February 28, 2017, Published: June 2017

iThenticate screening: March 06, 2017, English editing: May 27, 2017, Quality control: June 02, 2017

(C) 2017 The Authors. This is an open access article under the terms of the Creative Commons Attribution-NonCommercialNoDerivs License, which permits use and distribution in any medium, provided the original work is properly cited, the use is non-commercial and no modifications or adaptations are made. 
especially girls (3). According to previous studies, girls have more behavioral restrictions than boys at this stage (4, $5)$. These situations in early adolescence may lead to formation and intensity of anxiety and depression $(2,3)$. Stressful experiences can sensitize future tensions in mental and biological systems in adolescents, and may lead to an increase in reaction to depression and anxiety (6). Since reaction to stress is related to problem solving disorders, depression and anxiety can cause destruction in social and job performance, and the outcome can have a negative effect on life environment $(4,5)$. Studies show that depression in this period is associated with suicide, drug abuse, acute infectious diseases and low academic performance (7-9). Therefore, the identification of influenced people and offering the proper interventions is crucial. Studies show that demographic characteristics such as gender $(10,11)$, age, academic level $(12,13)$ and body mass index are associated factors for depression and anxiety, however the results of various studies are contradictory in this matter (7). These disorders have interference with intellectual, emotional and behavioral methods in adolescents, and if untreated can lead to unsuccessful education and life (3). Studies indicate that obesity is related to risk of depression and other mental disorders $(14,15)$, however there is prospective evidence for an association between obesity and anxiety disorder (16). Since obesity and common mental diseases such as anxiety and depression are the greatest public health challenges, clarity of the causes of these relationships are very important (17). Previous studies on anxiety, depression and their risk factors revealed an inequality in geographical and variety of data (18), therefore, to reach epidemiologic objectives, further studies in various regions are necessary. Usually, schools are the first stage to recognize life-threatening behaviors, so identification and determination of prevalence of anxiety and depression and also the proper interventions to reduce these factors seems to be essential. This study is aimed to determine the prevalence of anxiety and depression and their associations with BMI among high school students in Qazvin, Iran in 2013-2014.

\section{Material and Methods}

This cross-sectional study was a descriptive and analytical study in high schools in Qazvin, Iran (March 2013 to April 2014). Through a cluster sampling, 1,079 high school students were recruited from four different regions in the city. After a short briefing about the goals of the study and collecting the consent forms, participants were asked to fill the questionnaires. Out of 1,079 respondents, 39 left the study for personal reasons such as sickness and living place changes. Finally, the total number of 1,040 15 to19 year-old students attended the study with the response rate of $96.3 \%$. This study was approved by the ethical committee of Qazvin University of Medical Sciences and there were no harmful effects on respondents. The data collection was based on the self-administrative questionnaires. The questionnaire had two parts including demographic information (name, gender, age, educational status, height, weight and BMI) and assessing mental health status (Beck depression inventory and Beck anxiety inventory). The Beck depression inventory had 21 questions with multiple choice answers. The questions rated on a 4-point scale ranging from 0 to 3 based on the severity. The maximum total score was 63 of which 0 to 25 were considered as normal, 26 to 38 as mild depression, 39 to55 as moderate depression and 56 to63 as severe depression (19). Moreover, the Beck anxiety inventory questionnaire had 21 questions that had multiple-choice answers. The questions rated on a 4-point scale ranging from 0 to 3 . The questionnaire had a four factors structure to reveal anxiety symptoms including neurophysiological, autonomic symptoms, subjective, and panic. The highest score was 63 which 0 to 7 was normal, 8 to 15 was mild anxiety, 16 to 25 was moderate anxiety and 26 to63 was severe anxiety. Reliability and validity of the questionnaire was determined in previous studies and indicated as a strong instrument to measure anxiety (20). Height and weight of all respondents were measured using accurate and calibrated scales to calculate Body Mass Index $\left(\mathrm{BMI}=\right.$ weight $(\mathrm{kg}) /$ height $\left.^{2}(\mathrm{~m})\right)$. BMI was categorized according to classification of the Center for Disease Control (CDC, 2015) (21). Data were analyzed after data collection using SPSS-19. Descriptive analyses such as frequency and percentage for categorical variables and Mean \pm SD for continuous variables were used. Moreover, t-test was conducted to compare continuous variables and Chi-square was used for comparison of categorical variables. Pearson correlation analysis was conducted to show the correlation between variables, and pvalues less than 0.05 were considered statistically significant.

\section{Results}

The current study had a response rate of $96.3 \%$ and data was analyzed for 1,040 students. The mean age of respondents was $16.52 \pm 1.09$ years old. Table 1 shows the demographic information and mental health status of respondents in males and females. The table indicated that $499(48 \%)$ were females and $541(52 \%)$ were males. There was no significant difference in mean of age $(\mathrm{p}=0.0614)$ between males $(16.51 \pm 1.09$ years old $)$ and females $(16.54 \pm 1.1$ years old). The highest number of students were in class $2(35.3 \%)$ and it was followed by class $3(35 \%)$ and class $1(29.7 \%)$, and the difference was not significant for genders ( $>0.05)$. Moreover, Table 1 indicates that $61 \%$ of the respondents were at normal range for BMI, and it was followed by $14.7 \%$ underweight and $24.3 \%$ overweight and obesity. Being underweight was significantly higher in females while being obese was significantly 
higher in males $(\mathrm{p}=0.014)$. In addition, Table 1 indicates that the prevalence of depression symptoms and anxiety symptoms were $31.8 \%$ and $14.9 \%$, respectively. According to the results, depression symptoms in females (39.9\%) were significantly higher than males $(24.4 \%)(\mathrm{p}<0.001)$. In addition, anxiety symptoms in females were higher than in males $(17.2 \%$ vs. $12.8 \%$, respectively) $(\mathrm{p}=0.026)$. Figure 1 demonstrates that about one-fourth of the respondents $(23.75 \%)$ had mild-moderate depression symptoms and $8.08 \%$ were in severe range. The data for anxiety symptoms shows $11.07 \%$ mild-moderate and $3.75 \%$ severe. According to Table 2, students with depression symptoms which simultaneously had anxiety symptoms, obesity/overweight and underweight were $11.2 \%, 16.9 \%$ and $1.5 \%$ of all respondents. Moreover, the table shows almost the same results for anxiety symptoms which means respondents who had anxiety symptoms with depression symptoms were $11.2 \%$, with obesity/overweight were $4.5 \%$ and with underweight were $1.9 \%$. Table 3 shows the significant and positive correlation between depression symptoms and anxiety symptoms $(\mathrm{r}=0.256, \mathrm{p}<0.001)$ and between depression and BMI $(\mathrm{r}=0.333, \mathrm{p}<0.001)$, but there was a negative and significant correlation between anxiety and BMI $(r=-0.086, p=0.006)$.

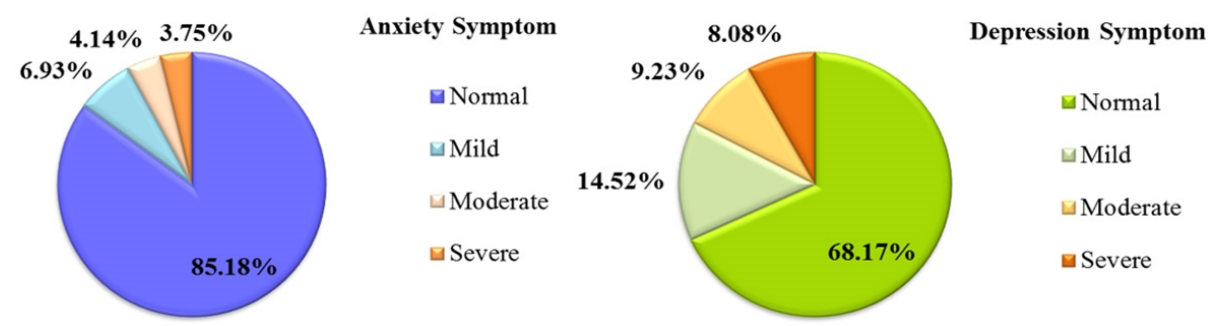

Figure 1: Anxiety and Depression Level in respondents.

Table 1: Demographic characteristics and mental health status of students [presented as number (\%)]

\begin{tabular}{|c|c|c|c|c|c|}
\hline \multicolumn{2}{|l|}{ Variables } & $\begin{array}{l}\text { Male; Mean } \pm \text { SD or } \\
\mathrm{n}(\%)\end{array}$ & $\begin{array}{l}\text { Female; Mean } \pm \text { SD } \\
\text { or } \mathrm{n}(\%)\end{array}$ & $\begin{array}{l}\text { Total; Mean } \pm \text { SD or } \\
\mathrm{n}(\%)\end{array}$ & $\mathrm{p}$-value \\
\hline Age (year) & & $16.51 \pm 1.09$ & $16.54 \pm 1.1$ & $16.52 \pm 1.09$ & 0.614 \\
\hline \multirow[t]{3}{*}{ Educational level } & Level 1 & $153(28.3)$ & $156(31.3)$ & $309(29.7)$ & \multirow[t]{3}{*}{0.491} \\
\hline & Level 2 & $191(35.3)$ & $176(35.3)$ & $367(35.3)$ & \\
\hline & Level 3 & $197(36.4)$ & $167(33.4)$ & $364(35)$ & \\
\hline \multirow[t]{4}{*}{ BMI $\left(\mathrm{kg} / \mathrm{m}^{2}\right)$} & Underweight & $62(11.4)$ & $91(18.2)$ & $153(14.7)$ & \multirow[t]{4}{*}{$0.014 *$} \\
\hline & Normal & $343(63.4)$ & $291(58.3)$ & $634(61)$ & \\
\hline & Overweight & $82(15.2)$ & $78(15.7)$ & $160(15.4)$ & \\
\hline & Obese & $54(10)$ & $39(7.8)$ & $93(8.9)$ & \\
\hline \multirow{2}{*}{$\begin{array}{l}\text { Depression } \\
\text { symptom }\end{array}$} & Yes & $132(24.4)$ & $199(39.9)$ & $331(31.8)$ & \multirow[t]{2}{*}{$<0.001^{*}$} \\
\hline & No & 409 (75.6) & $300(60.1)$ & $709(68.2)$ & \\
\hline \multirow{2}{*}{$\begin{array}{l}\text { Anxiety } \\
\text { symptom }\end{array}$} & Yes & $69(12.8)$ & $86(17.2)$ & $155(14.9)$ & \multirow[t]{2}{*}{$0.026^{*}$} \\
\hline & No & $427(87.2)$ & $413(82.8)$ & $885(85.1)$ & \\
\hline
\end{tabular}

* Significant $\mathrm{p}$-value at the level of $p<0.05$

Table 2: Depression and anxiety of respondents simultaneously with different levels of BMI

\begin{tabular}{|l|l|l|}
\hline Variables & $\mathrm{n}$ & $\%$ \\
\hline Depression symptom & 331 & 31.8 \\
\hline Depression symptom and anxiety symptom & 116 & 11.2 \\
\hline Depression symptom and obesity/overweight & 175 & 16.9 \\
\hline Depression symptom and underweight & 16 & 1.5 \\
\hline Anxiety symptom & 155 & 14.9 \\
\hline Anxiety symptom and depression symptom & 116 & 11.2 \\
\hline Anxiety symptom and obesity/overweight & 47 & 4.5 \\
\hline Anxiety symptom and underweight & 20 & 1.9 \\
\hline
\end{tabular}


Table 3: Correlation between depression, anxiety and BMI among respondents.

\begin{tabular}{|l|l|l|l|l|l|l|}
\hline Variables & \multicolumn{2}{|c|}{ Depression symptom } & \multicolumn{3}{|c|}{ Anxiety symptom } & \multicolumn{2}{l|}{ BMI } \\
\hline & $\mathrm{r}$ & $\mathrm{p}$-value & $\mathrm{r}$ & $\mathrm{p}$-value & $\mathrm{r}$ & $\mathrm{p}$-value \\
\hline Depression & - & - & 0.256 & $<0.001^{*}$ & 0.333 & $<0.001^{*}$ \\
\hline Anxiety & 0.256 & $<0.001^{*}$ & - & - & -0.086 & $0.006^{*}$ \\
\hline BMI & 0.333 & $<0.001^{*}$ & -0.086 & $0.006^{*}$ & - & - \\
\hline
\end{tabular}

* Significant $\mathrm{p}$-value at the level of $p<0.05$

\section{Discussion}

The current study showed 31.8\% depression symptoms among high school studens, which means about one-third of them had depression symptoms of varied intensity. The prevalence of depression among adolescents ranged from $4 \%$ to $8 \%(22)$. The results of the current study are comparable with the previous study by Zakeri et al. (23) which reported $29.7 \%$ and $11.5 \%$ the prevalence of depression and anxiety, respectively among students. In this study, there was a simultaneity for depression and anxiety and it was in line with the study by Assarian et al. (2006). They indicated that the simultaneity for depression and anxiety may be caused by several factors such as genetic, neurophysiology, neurochemistry, moods and mechanisms of interaction $(24,25)$. In the current study, mental disorder (anxiety and depression) was higher in girls compared to boys and the result was comparable with other studies with almost the same results $(7,8)$. These results were expectable according to the litarature which showed that gender is not a risk factor for depression in childhood, however increasing age and reaching adolescnce can increase depression among females but not in males. And also, being male was not the risk factor for depression along with increasing age and even showed a slight reduction in depression (22). The usage of cosmetic products and cosmetic surgery are high in a country where the consequences of apperance and sex roles are main risk factors for mental disorder (7). Women and men respond to the same stressors differently, and women are more vulnarable because of the sex differences in biological responses (sex hormons especially estrogen and progesterone), selfconfidence and coping (26). In the current study, the prevalence of overweight was higher than other studies in Iran and some countries such as China and Pakistan $(27,28)$. In Iranian stuides, the prevalence of overweight and obesity among students was $12.3 \%$ and $8.5 \%$, respectively (29). Moreover, in another study among Iranian students, the prevalence of underweight, overweight and obesity was $16.2 \%, 8.6 \%$ and $1.5 \%$, respectively and the prevalence of underweight was almost the same and comparable with the current study (30). In addition to gender, BMI had association with depression and anxiety. There was a poor and positive correlation between depression and BMI and also, the results presented that depression symptoms in obesity were higher than in underweight students. In line with this study, several researches showed that higher BMI may affect and increase the risk of depression $(15,31)$. The hypothesis in this context is based on biological mechanisms such as inflammation, hormonal system disorder and the risk of somatic diseases which may lead to secondary effects on the mental system (17). Moreover, obesity can apply its negative role through self-concept especially in females (16). On the other hand, results showed a very poor and negative correlation between anxiety symptoms and BMI, and thin students had higher anxiety symptoms compared to obese ones. In line with this study, other studies also confirmed the same results, and reported inconsiderable relation between obesity and anxiety $(16,32)$. Studies indicated that high BMI may affect the risk of suicide directly. This may be due to the effect of high BMI on several hormones such as tostestrone, neurotransmitters such as leptin as well as the serotonin levels. Since depression and other mental diseases are strong risk factors for suicide, their assessment and their association with demographic characteristics are very considerable $(33,34)$. According to results, BMI in boys was significantly higher than in girls but it was expected because Iranian boys attendance of weight loss programs is one-fourth of girls' attendance. Studies also showed that boys are less vulnerable than girls in the psychological consequences of obesity. In addition, in developing countries, increasing weight in boys compared to girls is more accepted for mothers $(23,35)$. Some limitations in the current study should be taken into consideration. The present study results are not generalized throughout the country and participants were selected in one district. Additionally, it is suggested to assess the association of some factors related to weight gain or wright loss with depression and anxiety among adolescents.

\section{Conclusions}

This study made a significant step forward in the report of mental disorder, and obviously showed that the prevalence of depression and anxiety is high among students. This study also indicated that gender and BMI have a significant effect on psychological symptoms. Therefore, effective interventions are necessary to improve these disorders. The effectiveness of the interventions should be assessed through self-report measures. One of the appropriate solutions is cognitive and behavioral therapies that need assessment of associated factors; however, the current study tried to consider this necessity. 


\section{Acknowledgments:}

The authors would like to thank two departments for their great support, Qazvin Department of Education, and Children's Growth Research Center of Qazvin.

\section{Conflict of Interest:}

There is no conflict of interest to be declared.

Authors' contributions:

All authors contributed to this project and article equally. All authors read and approved the final manuscript.

\section{References:}

1) Viner RM, Ozer EM, Denny S, Marmot M, Resnick M, Fatusi A, et al. Adolescence and the social determinants of health. Lancet. 2012; 379(9826): 1641-52. doi: 10.1016/S0140-6736(12)60149-4. PMID: 22538179

2) Buchanan GM, Seligman M. Explanatory style. Routledge: Taylor \& Francis; 2013.

3) Nolen-Hoeksema S. Gender differences in depression. Curr Dir Psychol Sci. 2001; 10(5): 173-6. doi: http://journals.sagepub.com/doi/abs/10.1111/1467-8721.00142

4) Barman P, Mahanta TG, Barua A. Social health problem of adolescent girls aged 15-19 years living in slums of Dibrugarh town, Assam. CEGH. 2015; 3: S49-S53. doi: 10.1016/j.cegh.2015.11.001.

5) Axelson DA, Birmaher B. Relation between anxiety and depressive disorders in childhood and adolescence. Depress Anxiety. 2001; 14(2): 67-78. doi: 10.1002/da.1048. PMID: 11668659.

6) Ellis BJ, Del Giudice M. Beyond allostatic load: Rethinking the role of stress in regulating human development. Dev Psychopathol. 2014; 26(1): 1-20. doi: 10.1017/S0954579413000849. PMID: 24280315.

7) Amarasuriya SD, Jorm AF, Reavley NJ. Prevalence of depression and its correlates among undergraduates in Sri Lanka. Asian J Psychiatr. 2015; 15: 32-7. doi: 10.1016/j.ajp.2015.04.012. PMID: 25998095.

8) Mushquash AR, Stewart SH, Sherry SB, Sherry DL, Mushquash CJ, MacKinnon AL. Depressive symptoms are a vulnerability factor for heavy episodic drinking: A short-term, four-wave longitudinal study of undergraduate women. Addict Behav. 2013; 38(5): 2180-6. doi: 10.1016/j.addbeh.2012.11.008. PMID: 23454875.

9) Buckner JD, Keough ME, Schmidt NB. Problematic alcohol and cannabis use among young adults: The roles of depression and discomfort and distress tolerance. Addict Behav. 2007; 32(9): 1957-63. doi: 10.1016/j.addbeh.2006.12.019. PMID: 17258398, PMCID: PMC1986746.

10) Said D, Kypri K, Bowman J. Risk factors for mental disorder among university students in Australia: findings from a web-based cross-sectional survey. Soc Psychiatry Psychiatr Epidemiol. 2013; 48(6): 935 44. doi: 10.1007/s00127-012-0574-x. PMID: 22945366.

11) Eisenberg D, Golberstein E, Gollust SE. Help-seeking and access to mental health care in a university student population. Med care. 2007; 45(7): 594-601. doi: 10.1097/MLR.0b013e31803bb4c1. PMID: 17571007.

12) Ibrahim AK, Kelly SJ, Adams CE, Glazebrook C. A systematic review of studies of depression prevalence in university students. J Psychiatr Res. 2013; 47(3): 391-400. doi: 10.1016/j.jpsychires.2012.11.015. PMID: 23260171.

13) Bayram N, Bilgel N. The prevalence and socio-demographic correlations of depression, anxiety and stress among a group of university students. Soc Psychiatry Psychiatr Epidemiol. 2008; 43(8): 667-72. doi: 10.1007/s00127-008-0345-x. PMID: 18398558.

14) Kivimäki M, Batty GD, Singh-Manoux A, Nabi H, Sabia S, Tabak AG, et al. Association between common mental disorder and obesity over the adult life course. Br J Psychiatry. 2009; 195(2): 149-55. doi: 10.1192/bjp.bp.108.057299. PMID: 19648547.

15) Bjerkeset O, Romundstad P, Evans J, Gunnell D. Association of adult body mass index and height with anxiety, depression, and suicide in the general population The HUNT Study. Am J Epidemiol. 2008; 167(2): 193-202. doi: 10.1093/aje/kwm280. PMID: 17981889.

16) Bjørngaard JH, Carslake D, Nilsen TIL, Linthorst AC, Smith GD, Gunnell D, et al. Association of Body Mass Index with Depression, Anxiety and Suicide-An Instrumental Variable Analysis of the HUNT Study. PloS one. 2015; 10(7): e0131708. doi: 10.1371/journal.pone.0131708. PMID: 26167892, PMCID: PMC4500562. 
17) Luppino FS, de Wit LM, Bouvy PF, Stijnen T, Cuijpers P, Penninx BW, et al. Overweight, obesity, and depression: a systematic review and meta-analysis of longitudinal studies. Arch Gen Psychiatry. 2010; 67(3): 220-9. doi: 10.1001/archgenpsychiatry.2010.2. PMID: 20194822.

18) Desouky D, Abdellatif IR, Salah OM. Prevalence and Comorbidity of Depression, Anxiety and Obsessive Compulsive Disorders among Saudi Secondary School Girls, Taif Area, KSA. Arch Iran Med. 2015; 18(4): 234-8. doi: 015184/AIM.008. PMID: 25841944.

19) Lasa L, Ayuso-Mateos J, Vazquez-Barquero J, Diez-Manrique F, Dowrick C. The use of the Beck Depression Inventory to screen for depression in the general population: a preliminary analysis. J Affect Disord. 2000; 57(1-3): 261-5. doi: 10.1016/S0165-0327(99)00088-9. PMID: 10708841.

20) Beck AT, Epstein N, Brown G, Steer RA. An inventory for measuring clinical anxiety: psychometric properties. J Consult Clinic Psychol. 1988; 56(6): 893-7. doi: 10.1037/0022-006X.56.6.893. PMID: 3204199.

21) CDS. About Child \& Teen BMI. 2015. Available from: http://www.cdc.gov/healthyweight/assessing/bmi/childrens_bmi/about_childrens_bmi.html.

22) Thapar A, Collishaw S, Pine DS, Thapar AK. Depression in adolescence. Lancet. 2012; 379(9820): 105667. doi: 10.1016/S0140-6736(11)60871-4. PMID: 22305766.

23) Zakeri M, Sedaghat M, Motlagh ME, Ashtiani RT, Ardalan G. BMI correlation with psychiatric problems among 10-18 years Iranian students. Acta Med Iran. 2012; 50(3): 177-84. PMID: 22418986.

24) Assarian F, Biqam H, Asqarnejad A. An epidemiological study of obsessive-compulsive disorder among high school students and its relationship with religious attitudes. Arch Iran Med. 2006; 9(2): 104-7. PMID: 16649349.

25) Alansari BM. Relationship between depression and anxiety among undergraduate students in eighteen Arab countries: A cross-cultural study. SBP. 2005; 33(5): 503-12. doi: 10.2224/sbp.2005.33.5.503.

26) Stoppard J. Understanding depression: Feminist social constructionist approaches. Routledge; 2014.

27) Warraich HJ, Javed F, Faraz-ul-Haq M, Khawaja FB, Saleem S. Prevalence of obesity in school-going children of Karachi. PLoS One. 2009; 4(3): e4816. doi: 10.1371/journal.pone.0004816. PMID: 19308262, PMCID: PMC2655713.

28) Orsi CM, Hale DE, Lynch JL. Pediatric obesity epidemiology. Curr Opin Endocrinol Diabetes Obes. 2011; 18(1): 14-22. doi: 10.1097/MED.0b013e3283423de1. PMID: 21157323.

29) Hajian-Tilaki KO, Sajjadi P, Razavi A. Prevalence of overweight and obesity and associated risk factors in urban primary-school children in Babol, Islamic Republic of Iran. East Mediterr Health J. 2011; 17(2): 10914. PMID: 21735944.

30) Montazerifar F, Karajibani M, Rakhshani F, Hashemi M. Prevalence of underweight, overweight and obesity among high-school girls in Sistan va Baluchistan. East Mediterr Health J. 2009; 15(5): 293-300. PMID: 20214144.

31) Simon GE, Von Korff M, Saunders K, Miglioretti DL, Crane PK, van Belle G, et al. Association between obesity and psychiatric disorders in the US adult population. Arch Gen Psychiatry. 2006; 63(7): 824-30. doi: 10.1001/archpsyc.63.7.824. PMID: 16818872, PMCID: PMC1913935.

32) Gariepy G, Nitka D, Schmitz N. The association between obesity and anxiety disorders in the population: a systematic review and meta-analysis. Int J Obes. 2010; 34(3): 407-19. doi: 10.1038/ijo.2009.252. PMID: 19997072.

33) Klinitzke G, Steinig J, Bluher M, Kersting A, Wagner B. Obesity and suicide risk in adults--a systematic review. J Affect Disord. 2013; 145(3): 277-84. doi: 10.1016/j.jad.2012.07.010. PMID: 22871535.

34) O'Connor RC, Platt S, Gordon J. International handbook of suicide prevention: Research, policy and practice. John Wiley and Sons; 2011. doi: 10.1002/9781119998556.

35) Flynn MA. Fear of fatness and adolescent girls: implications for obesity prevention. Proc Nutr Soc. 1997; 56: 305-17. doi: 10.1079/PNS19970034. PMID: 9168541. 